\title{
To "e-" or not to "e-"
}

Re-locating innovation in "electronic" decision-making

\section{Ben Li}

InnoLab, University of Calgary

\begin{abstract}
This paper presents evidence from three global organizations that "e-" does not modify decision-making relating to "democracy". Defining "e-" as shorthand for decision-making skills, tools, and patterns enabled by information and communication technologies (ICTs), including computer-mediated communication (CMC), it tests whether "e-" is an "incremental" innovation augmenting democracy as a decision-making pattern. It finds that "e-" acts as a "radical" innovation to democracy by providing different mechanisms used in place of democracy. It also finds that indicators of good democratic decision-making (participation, sustainability, and impact) reveal little about the ability of "e-" to achieve the same desirable goals to which democracy aspires.
\end{abstract}

Keywords: Innovation, Internet, decision-making, democracy, computer-mediated communication

Acknowledgement: This paper presents data arising from the author's previous thesis work conducted at the University of Calgary on open source innovation. The author thanks InnoLab colleagues and the anonymous reviewers for their insights.

T he new terms "e-participation" (e.g. Kaschesky \& Riedl, 2010), "e-democracy" (e.g., Blachfellner et al., 2009), and "e-government" (e.g. Ferro \& Molinari, 2010), modify "participation", "democracy", and "government", respectively, by prefixing shorthand for "electronic". The terms denote and assume that being electronic (digital or online) is not only a relevant difference between the new and old forms, but that being digital or online is the relevant and fundamental difference. But the terms tempt their users to focus only on the electronic gadgetry as though "participation", "democracy", and "government" would naturally follow from implementing "e-". "e-" as a modifier of existing concepts discourages thinking about "e-" as the new fundamental concept to be modified by "participation", "democracy", "government", and so on. Meanwhile, "e-" researchers and practitioners struggle to explain low numbers of active participants, poor sustainability, and low impact of "e-" democracy projects (e.g., Chadwick, 2008) that apparently achieve neither "e-" nor the desired democratic or social outcomes.

This paper presents data from three global organizations to empirically challenge the assumption that "e-" is a relevant modifier of-or innovation to-decision-making tools of "democracy". It defines "e-" as shorthand for decision-making skills, tools and patterns enabled by information and communication technologies (ICTs) supporting computer-mediated communication (CMC) (Garcia et al., 2009), along with the skills, social norms, and concepts required to operate those tools. It operationally defines "democracy" through its desirable characteristics indicated by participation, sustainability, and impact.

The innovation perspective identifies new products or practices (Schumpeter, 1942) by the extent that adopting novelty changes practices. This paper tests whether "e-" is an "incremental" innovation (Henderson \& Clark, 1980) augmenting existing capabilities of democracy as a decisionmaking toolkit, or whether "e-" is a "radical" innovation (Utterback, 1995) providing different capabilities than democracy as a decision-making toolkit. This paper finds that current indicators of "good" democratic decision-making (participation, sustainability, and impact) say little about the ability of "e-" to achieve the socially desired outcomes tracked by those indicators. 
This paper begins by introducing the three global organizations studied: Mozilla, Apache, and the American Registry for Internet Numbers; and this paper's approach to gathering and understanding data about the organizations. Section two highlights features of the three organizations as "e-" democratic decision-making bodies and shows that viewing "e-" as an incremental innovation to democracy does not explain the three organizations' activities or successes. The third section poses "e-" as a radical innovation to decision-making to explain how the three organizations' "e-" decision-making achieves the same goals as democratic decisionmaking without using the democratic toolkit.

This paper considers only those decision-making aspects of the three organizations engaging broad stakeholders to develop, advance or maintain their respective public infrastructures, and not routine operational decisions such as marketing strategies or choice of business service providers. It also does not study decision-making concerning adoption of laws by nation states. This paper also does not study uptake of ICT decision-making tools by the three organizations which were instantiated through the use of ICTs. But it does in passing illustrate that decision-making through extensive use of ICTs follows familiar political decision-making patterns.

\section{Mozilla, Apache, and ARIN as online democracies}

Broadly, this research identified and analysed instances of decision-making in three organizations, through the communications and actions of their stakeholders and leaders. It also identified and analysed the governance contexts in which such decision-making occurred.

The three organizations studied are the Mozilla Foundation for its Firefox web browser project, the Apache Software Foundation for its HTTP Server project, and the American Registry for Internet Numbers (ARIN) for its Policy Development Process. All make key decisions facilitating a global technological and social infrastructure. Three hundred million individuals use the Firefox web browser to retrieve and display web pages from 70 million web servers running instances of Apache HTTP Server. North American users connect to YouTube, Wikipedia, digg, and the U.S. Senate websites—running on Apache HTTP server (Netcraft, 2009)—via Internet Number Resources allocated by ARIN. By charter and necessity of international scope, the three organizations decide directions and actions overwhelmingly in the open using CMC venues and ICTs familiar to "e-" decision-making. Their use of elected leaders, broad consultation, and direct stakeholder action are generally common to democratic implementations. Their diverse functions, responsibilities, scales of responsibility, stakeholders, and problem domains are like many kinds of problems to which democracy has been applied, and for which ICTs are thought to be well-suited.

The three organizations express decisions and implementations as unambiguous procedures and computer code to meet stakeholders' online and offline needs and demands. Their stakeholders and participants use, develop, or mange CMC tools professionally. These organizations were therefore chosen for providing: very favourable conditions to use "e-" democracy, among the best conditions for examining "e-" decision-making processes, and diverse examples of pure "e-" decision-making processes.

This paper draws from more comprehensive research employing ethnography and content analysis to understand how the organizations conduct their innovation processes (Li, 2010). The present paper examines decisions from those innovation processes for communication about who participated in decision-making, how they participated, and the outcomes. Examples of ideas ("bugs") in sections 2 and 3 were selected to illustrate typical decision-making processes and exceptional departures. They are detailed in (Li, 2010). This paper first attempts to understand those communications and actions through a broad lens of "democratic" decision-making, and then through the alternative of "e-" decision-making. 


\subsection{Ideas of democracy}

Although exercising democratic practices by charter (Mozilla, n.d.; Apache, 2010; ARIN, 2010), the three organizations do not adopt particular theoretical models of democracy. Their actual practices combine elements familiar to deliberative democracy, direct democracy, and representative democracy. As such, "democracy" in this paper refers broadly to supreme power of decision-making being vested and exercised by those governed (Encyclopædia Britannica, 2010). The indicators selected for this paper are not specific to any particular model of democracy, and do not assume the organizations operate according to any particular democratic model, but reflect desirable features of democratic decision-making as indicated by the organizations' own ideals and by those from literature. The intent is to study the extent to which their tools and modes of function exhibit democratic characteristics.

\subsection{Context of the three open organizations}

As open online environments, each organization explicitly requires their projects' (operational and political) decision-making to be fully documented in public archives and databases. Such records trace contributors, ideas, decisions, and implementations so that stakeholders and the public may understand and contribute to the projects. Typical participants include business and social users, experts who help decide which ideas to implement, and experts who perform much implementation work. Such active stakeholders developed the organizations' decision-making systems to successfully meet broad stakeholders' needs.

The three organizations are U.S. Internal Revenue Code 501(c) tax-exempt corporations for educational, charitable, and scientific purposes; but perform somewhat broader functions in areas where state government has delegated authority (ARIN) or does not exercise authority (Apache and Mozilla). All three organizations employ formal bureaucracies to coordinate technical and social activities of the organizations. Although the three organizations are loosely interconnected by users and technologies-and are internally self-organizing, generally non-hierarchical, and not explicitly market-oriented-this paper does not address the three as environments of interorganizational network governance as envisioned by Benson (1975) or Rhodes (1996). Communication, cooperation, or decision-making across the three organizations were not observed, although some contributors to each organization referred to documents and activities in other open Internet infrastructure organizations and projects.

\subsubsection{Data collection}

All three organizations gathered new ideas, deliberated, and tracked decisions and implementations via mailing lists, and/or Bugzillas. Stakeholders and participants also employed wikis, blogs, social media tools, newsgroups, IRC, and other $\mathrm{CMC}$ venues-and rare in-person meetings-but participants rarely referenced such other venues in official documentation when making particular decisions. (Those other venues were used for organizational strategic planning, and for communicating detailed technical information to support implementation, but rarely to make final decisions not previously deliberated on mailing lists or Bugzillas.) From the participants' perspective, the Bugzillas and mailing lists were both necessary and sufficient to make informed decisions; therefore the research reports only data from those channels.

The archived contents of each project's public discussion venue (a mailing list) and implementation venue (a mailing list and/or Bugzilla) for an approximate one-year period between summer 2008 and summer 2009 were downloaded and analysed. The time periods were chosen to avoid breaks in periods of major activity (Table 1). Instances of various kinds of communication and activity were counted using Thunderbird to visualize mailing list archives, and by interrogating search interfaces on the organizations' Bugzilla websites. The number of constituents and third party modules of each project were gathered from official project documentation (websites) or estimated from third-party sources if no official values were available (Table 2). 
Table 1: Study periods for data collection at three projects studied.

\begin{tabular}{|l|l|l|l|}
\hline Project & Versions included & Start date of data & End date of data \\
\hline Mozilla Firefox & $3.0-3.5 .2$ & June 17, 2008 & August 2, 2009 \\
\hline Apache HTTP Server & $2.2 .9-2.2 .13$ & June 14, 2008 & August 8, 2009 \\
\hline ARIN PDP & Policy proposals 73-97 & June 5, 2008 & June 12, 2009 \\
\hline
\end{tabular}

The numbers of items (ideas, enhancements logged, changes implemented, and features) at each stage of the projects' decision-making processes were recorded for the same period (Table 2). However, such counts did not track individual ideas as they moved through the processes. This approximation was justified as follows: Originators of ideas consistently move (or are encouraged to move) their viable ideas into the formal workflows within a short time (perhaps a month) out of individual interest. The projects are well established in their processes and resources available to receive and deliberate ideas, remaining consistent for at least two years before the study period. Changes in attention and resources available to implement ideas (e.g., meetings and interns) are cyclical but occur annually or more frequently. Therefore, an idea anywhere in a project's process three years prior to the study period would be subject to substantially the same conditions as an idea at a comparable stage during the study period. Exact numbers of items each year vary by the popularity or urgency of particular concepts, but their relative magnitudes vary little from year to year, nor across open organizations in addition to those reported presently (Li, 2009).

Figure 1 depicts the three organizations' formal configurations as specified in the organizations' charters and internal policies. Firefox is developed within Mozilla's faceted corporate structure, requiring multiple levels and kinds of review and action. Apache uses a fused cooperative structure in which every participant may exercise most kinds of decision-making. Finally, ARIN employs a linear bureaucratic process and separation of powers. These diverse organizations all strive to use open and inclusive processes.

Like a non-governmental organization (NGO), Apache provides specialized technical products, services, and project management to support development activities implemented on the ground by other parties. But, unlike many NGOs, Apache readily permits any technically competent individual from any government to join, and receives no government funding. It was formed to develop and maintain its core product, the Apache HTTP Server, which arose from personal collaborations among individuals at several public U.S. universities. The Mozilla Corporation, wholly owned by the Mozilla Foundation, employs paid business staff to publish consumer software (including Firefox) from which the company earns profit (via an arrangement making Google its default search engine). The standards and environment enabling Firefox arose from foundations laid by the National Center for Supercomputing Applications (NCSA), the European Organization for Nuclear Research (CERN), and the World Wide Web Consortium (W3C). ARIN is responsible for overseeing and administering specific functions related to Internet Number Resources in a specific geography, similar to the responsibilities of a state regulator or government agency. Unlike Apache and Mozilla which emerged from constituent efforts, ARIN originated as a service provider built by the U.S. government out of an agreement among several international and intergovernmental regulators (Karrenberg et al., 2001), with the goal of enabling stakeholders to contribute to their own regulation (ARIN, n.d.). Thus, the three represent diverse participatory organizations producing related outputs. 


\section{Legislative Executive Judicial}

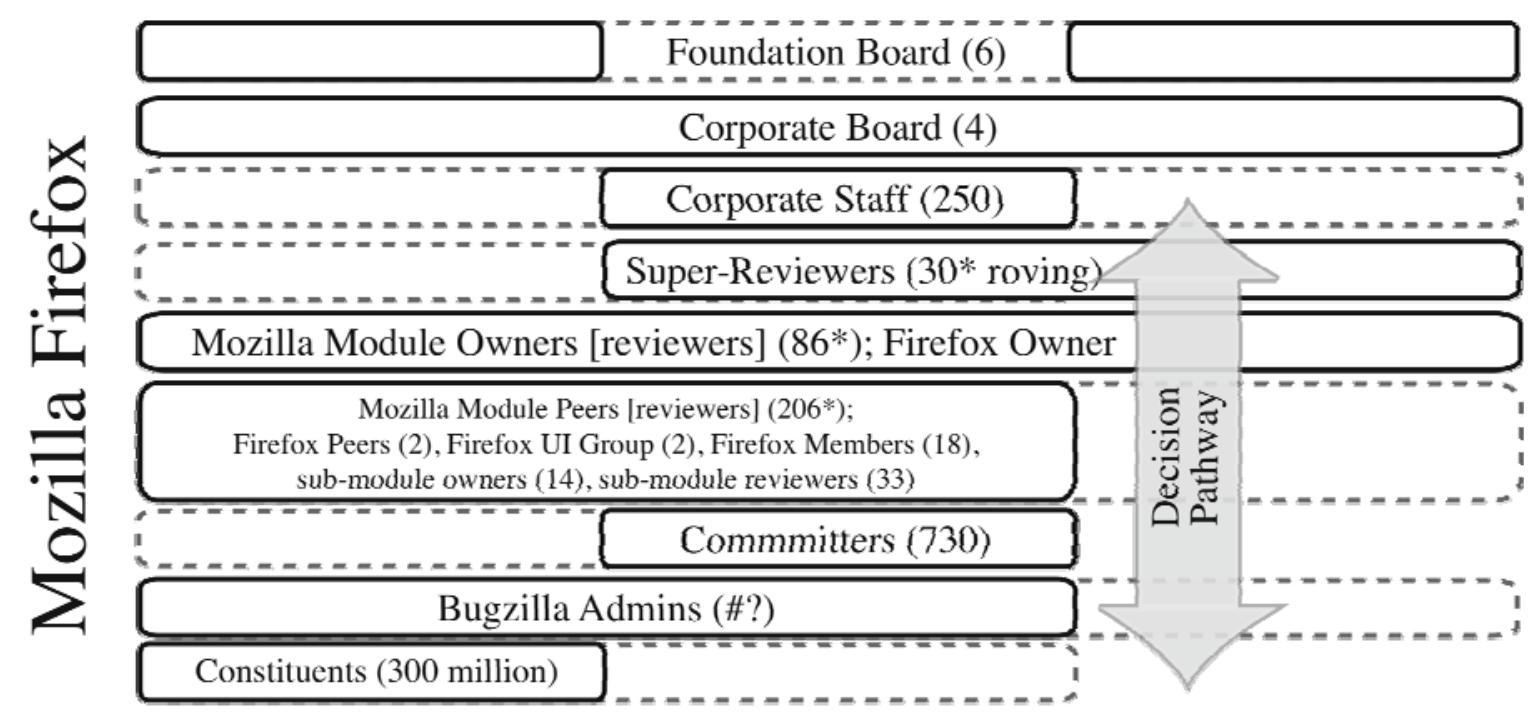

990 bureaucrats, 260 FTE
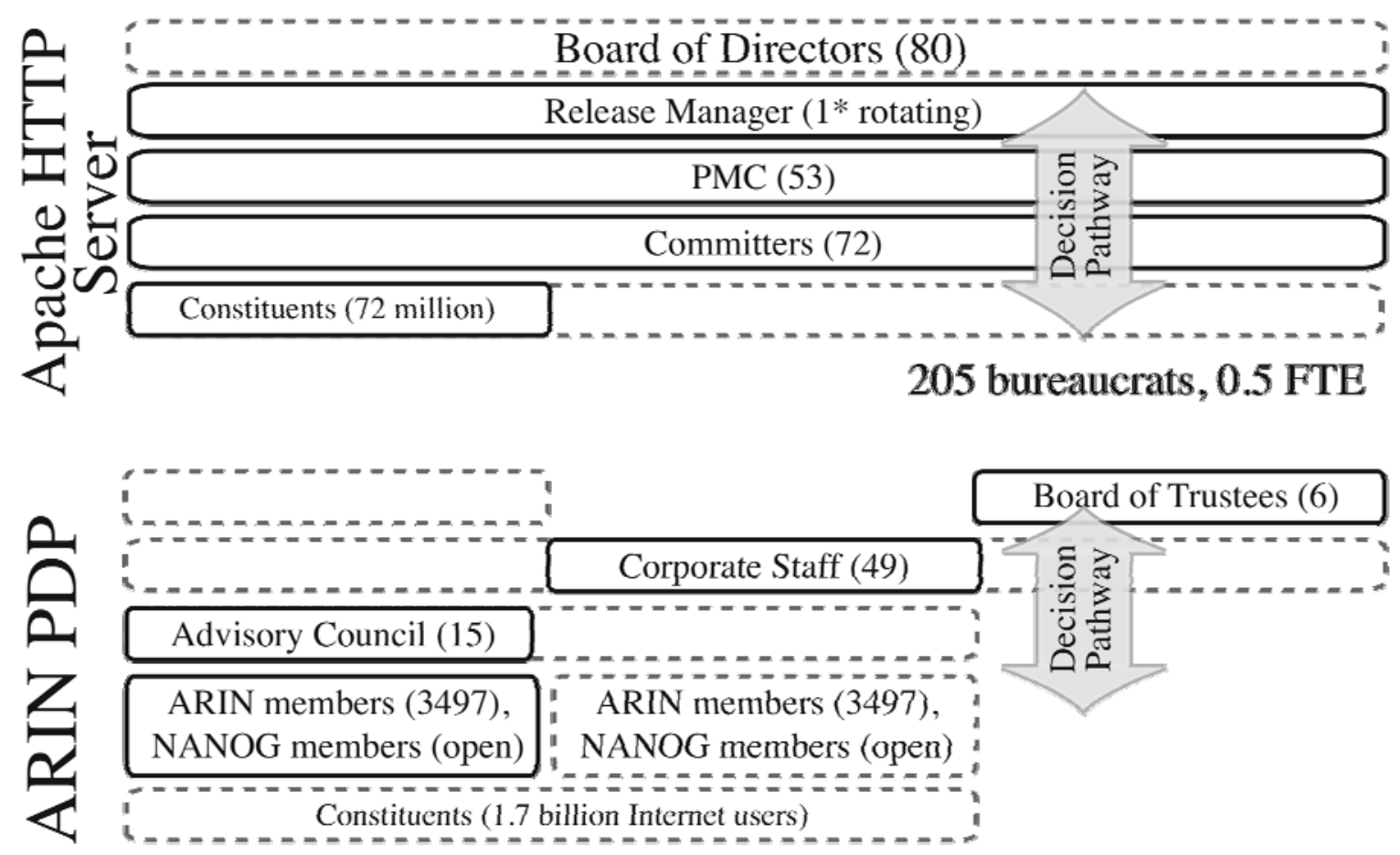

70 bureaucrats, 55 FTE

Figure 1: Formal decision-making structures of organizations studied (reproduced from Li, 2009) 
Table 2: Development, government, and demographic statistics, 2008-2009 study period (adapted from Li, 2010).

\begin{tabular}{|c|c|c|c|}
\hline Project & Mozilla Firefox & $\begin{array}{l}\text { Apache HTTP } \\
\text { Server }\end{array}$ & ARIN PDP \\
\hline \multicolumn{4}{|l|}{ Development } \\
\hline $\begin{array}{l}\text { (A) Changes proposed in } \\
\text { discussion list }\end{array}$ & 21038 & 738 & 315 \\
\hline $\begin{array}{l}\text { (B) Enhancements or policy } \\
\text { proposals ("bugs") }\end{array}$ & 1341 & 96 & 24 \\
\hline (B/A) Success rate & $6 \%$ & $13 \%$ & $8 \%$ \\
\hline $\begin{array}{l}\text { (C) Enhancements } \\
\text { implemented or policies } \\
\text { adopted }\end{array}$ & 129 & 19 & 11 \\
\hline$(\mathrm{C} / \mathrm{B})$ & $10 \%$ & $20 \%$ & $46 \%$ \\
\hline New features advertised & 138 & 141 & 11 \\
\hline $\begin{array}{l}\text { Ideas proposed by one-time } \\
\text { contributors (OTC) }\end{array}$ & $81 \%$ & $93 \%$ & $77 \%$ \\
\hline Adopted ideas by OTC & $58 \%$ & $85 \%$ & $61 \%$ \\
\hline \multicolumn{4}{|l|}{ Government } \\
\hline Stakeholders & $\begin{array}{l}300 \text { million Firefox } \\
\text { users }\end{array}$ & $\begin{array}{l}72 \text { million web } \\
\text { hosts run Apache } \\
\text { HTTPD }\end{array}$ & $\begin{array}{l}>1.6 \text { billion Internet } \\
\text { users or }>3,000 \\
\text { ARIN members }\end{array}$ \\
\hline $\begin{array}{l}\text { Active participants who } \\
\text { proposed changes on } \\
\text { discussion list }\end{array}$ & 14331 & 610 & 203 \\
\hline Participation rate & 5.3E-05 & 8.5E-06 & $1.3 \mathrm{E}-08$ or $6.7 \mathrm{E}-02$ \\
\hline Authorized committers & 800 & 120 & 15 \\
\hline $\begin{array}{l}\text { Formal government size } \\
\text { (includes committers) }\end{array}$ & 1253 & 207 & 70 \\
\hline \multicolumn{4}{|l|}{ Demographics } \\
\hline Project establishment year & 2004 & 1995 & 1997 \\
\hline Market share & $24 \%$ & $46 \%$ & 100\% N. America \\
\hline Revenues & $\$ 75,000,000$ & $\$ 199,938$ & $\$ 11,600,000$ \\
\hline Expenses & $\$ 33,000,000$ & $\$ 104,167$ & $\$ 11,300,000$ \\
\hline Profits & $\$ 42,000,000$ & $\$ 95,771$ & $\$ 300,000$ \\
\hline $\begin{array}{l}\text { Number of recognized } \\
\text { third-party modules }\end{array}$ & 10317 & 505 & $>24$ \\
\hline
\end{tabular}

\subsection{Decision-making by the numbers}

All three projects reduced many ideas to a few implementations (Table 2). The institutively and intuitively most accessible project, Firefox (almost any Internet user could conceive a meaningful improvement to a web browser), received more ideas and generated more accepted changes (implementations) than ARIN which had the highest barriers to entry (few individuals are qualified to make suggestions about Internet architecture). The only notable but unremarkable relationship 
observed between organizational configuration and implementation outcomes is that large bureaucracy co-occurs with many ideas discussed and many stakeholders.

Examining participation reveals details of the projects' decision-making mechanisms. The simplest way for stakeholders to participate in the projects was to note a deficiency or suggest an idea. A more difficult contribution would be to facilitate discussions or implement ideas on behalf of the projects. The most challenging would be to develop and maintain a third-party module to provide specific new functionality. Participants' apparent preference for socially mediated collaboration over formal bureaucratic forms is familiar to the network governance literature (e.g., as reviewed by Jones et al., 1997). However, that the pluralistic organizations work in open but informal patterns departs from assumptions about required formal mechanisms of democracy.

Table 2 shows over ten thousand Firefox users participated by contributing ideas or developing modules to extend the web browser. Less than a thousand individuals participated in the Apache HTTP Server project by contributing ideas or through module development. And very few public individuals participated in ARIN's Policy Development Process, although relatively many of its three thousand members (mostly network operators) participated in governing and policy development. Each organization depended heavily on the ideas of one-time contributors as sources of enhanced capabilities, and on the work of relatively small cadres of repeat contributors and bureaucrats to maintain developed capabilities.

\section{Evidence against "e-": participation, sustainability, and impact}

As highlighted above, the mere existence of online infrastructure does little alone to induce "e-" participation, decision-making, or outcomes. The SourceForge collaborative service provides "e-" infrastructure at no monetary cost to over 230,000 projects (SourceForge, 2010), yet tens of thousands of their projects have produced no discernible decisions or output. As the disconnect between capital and outputs in the three organizations studied suggests, stakeholders depend more on the human community behind "e-" for interaction than on the "e-" infrastructure.

Using cases from 2008-2009, the following section tests the hypothesis that "e-"-as an incremental innovation to democratic decision-making-yields a difference in the way the organizations made democratic decisions than without "e-". The hypothesis would be supported by evidence of five kinds of innovation-new products, new processes, new sources of raw material, new organizational configuration, or new markets (Schumpeter, 1942)—involving "e-" and resulting in enhanced participation, sustainability, and impact.

\subsection{Participation}

Participation is a key and desirable feature and measure of well-functioning implementations of democracy (Morlino, 2002; USAID, 1998). To participate in a democratic decision-making process, one must know that the process exists. Provided input is only meaningful if it is understood and used for decision-making by the organization (Arrow, 1974). And decision-making is only legitimate if all rational choices are considered and attainable.

\subsubsection{Knowledge and technical accessibility for participants and leaders}

"e-" offers the advantage and expectation that-through its online deliberations and policies indexed by search engines-every interested stakeholder could know everything about a decision. Knowledge of a decision-making process, and specific technical knowledge, are required for effective democratic participation (Dahl, 1994). If "e-" augments democratic decision-making, we would expect to detect a larger quantity of unique information from stakeholders reaching decisionmakers via efficient "e-" channels than via non-"e-" channels. When non-"e-" channels were used to meet democratic requirements (e.g. paper documents and board meetings required by U.S. law), the organizations adapted ICTs to present the contents of those communications (e.g. noninteractive images of documents and video recordings). Capabilities of ICT channels were not 
adopted to achieve the organizations' desired knowledge sharing or participatory outcomes. No single stakeholder (expert or novice) could have resources to internalize all relevant information about any particular decision from the concurrent sets of many. The organizations used familiar data minimization techniques to aggregate and de-personalize each contributor's input (e.g., Mozilla's use of "bug janitors" to categorize and de-duplicate stakeholder input). Neither operational leaders (knowledge experts), nor organizational leaders (stakeholder trustees), gained any mechanism through "e-" to compel volunteer contributors or stakeholders to become informed.

\subsubsection{Decision-making capability}

Effective decision-making requires access to appropriate and relevant information, people, materials, and time (Rowe \& Frewer, 2000). "e-" bureaucracy should be easy to follow and understand via fully and openly documented processes, and project experts and leaders should interpret among technical, bureaucratic, and stakeholder audiences. We expect "e-" bureaucracies could be smaller than without "e-" while better serving many more stakeholders since stakeholders and bureaucrats could focus time and attention on substantial problems rather than on internal navigation. But bureaucracy size did not relate to stakeholder population size but did scale with the number of active stakeholders, and some bureaucrats routinely used procedures to slow or accelerate decision-making and implementation against the apparent wishes of some stakeholders. If "e-" eases democratic decision-making, something like a new form or use of precedent or case law of, and for, "e-" interactions should arise. None did. Each organization employed familiar democratic dispute resolution tactics, but there was no sharing of decision-making expertise or precedents across communities specifically attributable to "e-". Problems of offline bureaucracies were also reproduced. Leaders had their own work approved in hours, but delayed new contributors' efforts by years in Apache HTTP Server bug 34607. Although starting materials (source code) were freely available, few participants had the technical knowledge or resources to build systems to experiment with possible alternative decisions. Relevant contributed information recorded by the "e-" infrastructure may not always be expressed in decisions, despite stakeholder objections to the contrary. Nine years of user input and evidence preceded action on Firefox bug 40848 , which was implemented outside the prescribed democratic process.

\subsubsection{Discussion and consensus-making}

Public deliberation and discussion are critical for engagement and accountability in democratic decision-making but are ephemeral and require face-to-face interactions (Carpini et al., 2004). The non-physical format of "e-" should allow free and open discussion across time and geography among stakeholders and representatives. We would expect different varieties of input to come from "e-" channels than from existing channels. In practice, stakeholders referred to online discussion archives (e.g., recalling video-recorded discussions about ARIN policy proposal 2008-4), language barriers were mitigated through iterated refinements of concepts, participants cited evidence from a variety of formal and informal CMC sources (e.g., citations of Google and Microsoft engineering in Firefox bug 40848), and stakeholders often freely and publicly contradicted leaders and each other but reached satisfactory (to participants) outcomes. However, experts criticized novices for using inappropriate channels to provide input (Mozilla and Apache operate dozens of discussions each), and some stakeholders confused project leaders' personal public online communications (e.g., blogs) with official communications. "e-" added little to mitigate or compound existing challenges.

"e-" infrastructure provided facilities for formally voting on almost every decision, but they were not used in familiar democratic ways. Voting systems were infrequently used despite being enabled by default (two dozen votes were cast about changes in Firefox affecting 300 million stakeholders). Apache allowed some but not all stakeholders to cast contingent or advisory votes as real numbers ranging from -1 to 1 to indicate degree of (dis)agreement (Apache Software Foundation, 2009). All three organizations formally and operationally preferred input from active contributors with technical merit over all others, contrary to the idea of "e-" incrementally enhancing equal voting for all. 


\subsection{Sustainability}

Sustainability is analysed in three senses: legacy sustainability to retain value from prior decisions and investments (Donovan, 2007); weak sustainability to develop and repeat a capability (USAID, 1998); and strong sustainability to leave stakeholders and their environment in a better condition (USAID, 1998; World Commission on Environment and Development, 1987).

\subsubsection{Legacy sustainability}

In theory, "e-" enables decisions and outputs to be fully specified and open for others to easily understand and adapt the work without rebuilding or repeating previous efforts. Such accumulation of work and precedent underpins democratic judicial, legislative, and executive apparatus (Donovan, 2007). If democratic decision-making were enhanced by "e-" we would expect participants to frequently refer to stakeholders and results from other "e-" democratic work, since expert project stakeholders would be made aware of the state of the art via "e-". In reality, the projects manually (re)identified stakeholders potentially affected by current decisions, actively sought to minimize disruptions to stakeholders who depended on overturned decisions, and used different decision-making methods for changes with minimal or broad anticipated effects on current stakeholders (e.g., efforts to accommodate both the American and European users' security models in Firefox bug 327181). The records available through "e-" facilitated recall of some internal and external information, but also overemphasized some historic concerns over contemporary needs.

\subsubsection{Weak sustainability}

Democracy seeks to be sustainable as an interactive institution (Bunce, 2003) and in providing durable benefits to stakeholders (Plater, 2006). Therefore, "e-" should provide new kinds of interaction to new kinds of stakeholders or in new democratic contexts (Davies \& Lithwick, 2010). In practice, "e-" facilitated the same kinds of dialogs and discussions as without "e-" but removed many of the personal tacit cues from all kinds of interactions leading to predictable confusion about intent. Some representatives exploited familiar kinds of knowledge gaps and bureaucratic tactics to dissuade interactions with stakeholders. "e-" provided supplementary opportunities to interpret previous communications, and enabled some discussions to carry on for years in Bugzillas with minimal loss of context (and without encouragement to conclude). However, only a few participants routinely referred to digital minutes to inform decisions as they would Hansards (e.g., contributors who referred to public work logs and discussion notes in Apache HTTP Server bug 44427). "e-" provided access to historic stakeholder inputs, but "e-" alone did not help participants at Firefox categorize or understand their contexts. Many stakeholders did not search others' ideas before contributing their own duplicates (e.g., the nine duplicates of Firefox bug 40848), which leaders treated as redundant rather than amplifying.

\subsubsection{Strong sustainability}

"e-" should enable more than current capabilities in providing, collecting, and storing information about democratic decision-making efforts, and leave a platform from which future participants can learn and perform better (e.g., Waller et al., 2001). In reality, Apache and Mozilla expend increasing resources for diminishing returns to manage old inputs and human resource problems that remain unsolved by adding "e-". (ARIN employs a policy development timeline that operationally ensures decisions are made within 12-18 months.) Except Mozilla's public release of its Bugzilla software (used by the Apache HTTP Server project and others), the projects lack formal mechanisms to routinely share or receive knowledge with comparable projects about improving on their use of "e-" decision-making tools. "e-" did not enhance participants' reuse or referral to previous work in any novel manner, and decisions remained based on knowledge local to each project despite plenty of open interfaces for sharing. 


\subsection{Impact}

Beneficial changes and enhanced conditions for stakeholders are socially desired outcomes of democratic processes. Those with responsibility to make or implement decisions should respond to changing needs of stakeholders to provide those outcomes.

\subsubsection{Accountability and transparency}

To evaluate how well decisions have been implemented via democratic decision-making, it is essential for stakeholders to strive for both political and managerial accountability and transparency (Christensen \& Lægreid, 2002). As an expression of openness, "e-" should prevent stakeholders from purposefully or negligently deciding in a non-democratic manner since all stakeholders could inspect everything. We would expect stakeholders to derive new ways to evaluate and discuss accountability (of individuals to their decisions) based on open data. In practice, some contributors knowingly made anti-democratic anti-system (and counter-productive) decisions in the open (e.g., an assignee of Firefox bug 40848 who openly threatened users and denigrated their input), while other stakeholders attempted to use traditional social mechanisms to persuade each other to be accountable (e.g., discussions about disclosures of personal and corporate interests in ARIN policy proposal 2008-7). Others still, appealed to bureaucrats and procedure for decisions in their favour in the open and through back channels. Despite the "e-" environments being open and data being available (and sometimes obvious, such as participants' use of corporate e-mail addresses), individuals' affiliations or other motives were not frequently disclosed or considered in decisions with potential conflicts of interests. "e-" provides accessible tools for stakeholders to track and evaluate leaders' and organizations' commitments and actions, but the tools were rarely used, let alone used to enhance democratic processes.

\subsubsection{Reflexivity}

Broadly, mutual stakeholder understanding, cooperation, and success are required to address needs identified by stakeholders (as reviewed by Johnsen et al., 2005). "e-" decision-making should provide better (faster, less expensive, more effective) responses to individual stakeholder needs and concerns using democratic patterns than without "e-". Therefore, "e-" should enable new classes of problems to be addressed on a more timely or efficient basis via votes, public consultations, and other democratic mechanisms. In reality, some "e-" response cycles remained long (months to years), thick user satisfaction problems fought for attention with easy technical problems (e.g. implementing SNI was a simple technical decision in Apache bug 34607 but exposing the functionality required much deliberation in Firefox bug 327181). Inputs from many stakeholders did not efficiently reach decision-makers, and stakeholders who never returned to "e-" discussions could hardly be informed of decisions affecting them. It is no surprise that people, not ICT tools, remained the reflexive element, nor that democracy automated by "e-" reduced motive to provide personal responses. More broadly, CMC tools may have helped to elect President Obama in 2008 in the U.S., but it's unclear whether the record millions of Americans participating in Obama-related "e-" democracy have directly generated any desired state policy outcomes since.

\subsubsection{Outcomes}

Democratic implementations seek to produce desired outcomes (Kirlin, 1996) having value gained through a democratic process (Pildes \& Anderson, 1990). Stakeholders could not presumably obtain similarly valued outcomes through non-democratic processes. "e-" as an process innovation to democracy should better obtain such outcomes than without "e-". If so, we would detect new forms of desired outcomes being created through more stakeholders participating in previously inaccessible parts of decision-making or implementation. But "e-" did not provide. First, leaders, not stakeholders, continued to dominate how the values of possible actions and characteristics of implemented changes were defined. Some leaders role-played as various 
stakeholders during design, implementation, and testing because relatively few affected stakeholders participate (e.g., the two dozen contributors out of 3,000 ARIN members who worked through likely scenarios about stakeholders absent from discussions about ARIN policy proposal 2008-7). Second, the forms of outcomes desired by the vast majority of stakeholders remain constant. They sought immediate beneficial outcomes, rather than sustainable outcomes designed for the future, and generally only provided direct input when begged to do so by leaders. Third, a small portion of stakeholders exercised exceptional influence without actively engaging the vast majority. "e-" did not correct this deficiency duplicated from state democracies. Fourth, user input correctly overrode leaders' decisions and outcomes in some cases (Firefox bug 404109), but stakeholders still had to rely on negative and reactionary publicity. Overall, CMC may have facilitated users to provide input about anticipated or actual outcomes via "e-", and some reactions may been hastened, but the organizations rarely openly connected learnings from mistakes to policy or processes changes to improve future outcomes.

\subsection{Summary of evidence of "e-" as an innovation to democracy}

Although "e-" provided a few new benefits and harms, it did not do so by extending democracy. Enhancing democratic decision-making with "e-" did not produce phenomena benefitting democratic decision-making in some cases, and was contrary to democratic decision-making in others. In both typical and deviant patterns of decision-making, three of the most established "e-" decision-making environments show few, if any, substantive enhancements by "e-" to their democratic decision-making practices. "e-" is at most an inconsequential incremental innovation to democratic decision-making (if it must supplement the democratic paradigm at all).

\section{Evidence supporting "e-" participation, democracy, and government}

Despite enthusiasm for enabling willing and able participants to engage via Web 2.0 ICTs, this latest thinking about "deliberative-collaborative e-Democracy" (Petrik, 2010) and the like remain trapped in viewing public decision-making through the lens of the democratic (protocol) state (scale) as the primary provider (source) of government (organization), and resources (rules and data) for the people (agenda). However, the substrate for "e-"-presently the mostly flat public Internet-is by design indifferent to who uses which protocols to communicate what data at which scale to whomever else under whichever agenda or rules of organization.

This section unwinds the above case against "e-" as a modifier to democratic decision-making to argue that "e-" is a generic radical innovation in decision-making in its own right.

Recall that software is almost a perfect and unambiguous expression of policy about how to handle allowable inputs, actions, and outcomes. It is expressed in a testable logic, and its execution is (usually) unambiguous. Recall also that although the three projects studied represent the best possible conditions for "e-" to succeed as a democratic decision-making tool, their processes measured poorly by several important indicators of democratic decision-making.

What if the contribution of "e-" is not to yield more participation, better representation, or more distinct items of contributed information (as the democratic model and indicators would expect) but to enable leaders and stakeholders to make good decisions with less information or cost (as generally desired of decision-making)? The three organizations provide evidence that a small handful of active, knowledgeable, and interested stakeholders are sufficient to produce satisfactory outcomes to meet most needs of most stakeholders. This proposition opposes the democratic assumption that more input from more stakeholders yields better outcomes.

Some broad clues suggest exploring this possibility. First, none of the three organizations studied would have been enabled without "e-" as a way to organize work, and they have produced socially valuable outcomes. Second, organizations must embed democratic interfaces to interact with the legal and commercial realms in their surrounding meatspace, but the three organizations all chose not to internally use democratic apparatus to make most substantial decisions. Third, 
given the blank slates available, each organization developed very similar "e-" processes to frame stakeholder input and decisions. That the "e-" process satisfied diverse demands of billions of stakeholders at local, continental and international scopes with infinitesimal participation rates and little input, while voters perpetually complain about state policy despite double-digit participation rates, suggests something new or better or at least different about "e-", unrelated to democracy.

\section{1. "e-" does not incrementally innovate on democracy}

From the innovation perspective, new "radical" innovations to technology are expected to initially perform less well than time-tested technology evolved and optimized from many small "incremental" innovations. Discovering and exploiting the capabilities of "e-"-required since existing competencies in democratic decision-making may no longer apply-would surely require some time and experimentation. The three organizations show that even among highly complex communities, sophisticated and broadly reaching decisions can be made using "e-" to the net benefit of all participants, without partisan hostility and exclusion typical of high-risk single shot decision-making events such as votes.

\subsection{Impact}

Benefits from using "e-" as a decision-making tool may be expressed in terms of the same goals of democracy-outcomes, reflexivity, and accountability—but using different indicators.

Outcomes: Within the three organizations studied, providing an interoperable world wide web yields value expressible in democratic policy-making terms of economy, education, and social wellbeing. We also gain value not expressible in terms of democratic state governance indicators. For example, no input/output measures appropriately show gains from using "e-" to decide features of the online ad blocking software AdBlock Plus for Firefox, even though the dollar value of unseen ads may be calculated for advertisers and users. Democracy implies the importance interpersonal networks and informed representatives, which are both explicitly documentable through "e-". Such dynamics are not new ideas to social and political economy; but are struggles of democratic governments and corporate bodies. (Note the worldwide plethora of ineffectual laws attempting to regulate "e-" interactions: the Communications Decency Act, the Digital Millennium Copyright Act, the No Electronic Theft Act, and the CAN-SPAM Act.) Democracy could hardly consider the social value of an idea embodied in an open software package (it struggles enough with generating benefits from explicit intellectual property), yet thousands of open source programmers try to translate ideas into positive outcomes for anonymous stakeholders daily via "e-".

Reflexivity: The relatively poor apparent impact of "e-" only holds assuming "e-" provides similar impacts as democratic decision-making. However, "e-" as a radical innovation would not necessarily produce the same superficial measures-let alone score higher-as existing measures and indicators for democratic decision-making. Despite (presumably) mobilizing meaningful indicators to enhance effectiveness, democratic decision-making implementations routinely expend more resources to produce fewer, less durable, and less timely stakeholder interactions with fewer stakeholders than "e-" in the three projects studied. Election candidates routinely expend $\$ 10^{1}$ (several dollars) per elector every several years to collect a few bits of preference information on which to make wide-reaching prospective policy decisions about topics unknown in advance, usually to great elector dissatisfaction. The "e-" systems studied expended up to $\$ 10^{-2}$ (pennies) per eligible stakeholder close to moments when decisions are informed and required, generating little stakeholder objection, without reducing sophisticated preferences to 'yes' or 'no'. "e-" responds better to at least some types of stakeholder needs in time, cost, responsiveness, and quality.

Accountability and transparency: "e-" does not ensure a contributor's every input or action becomes expressed directly in decisions or outcomes. It excels in ensuring that each input can be considered before, during, and after decisions are made, so that stakeholders, and not necessarily bureaucracy, determine when inputs are relevant (e.g., Mozilla bug 40848 took nine years to begin implementation under pressure from stakeholders and competitors, but noted in most instances 
why stakeholder input was ignored). In "e-", reprisal for poor actions and decisions is frequently to collaboratively correct the flaw, not to oust the wrongdoer through elections. "e-" has excelled at organizing efforts and resources outside state jurisdiction, but no conceptual reason prevents "e-" from operating similarly on interests currently within state jurisdiction. "e-" could achieve a super set of the accountability and transparency goals (the socially desired outcome) as democratically demanded by citizens, without necessarily being bound to democratic mechanisms.

\subsection{Sustainability}

Similar arguments as above obtain when considering sustainability. As with the democratic toolkit, if "e-" is sustainable, using "e-" should leave its stakeholders' shared environment more robust not by counting electors, but via routine consideration of past, present, and future needs.

Strong sustainability: "e-" decision-making environments are internally indefinitely sustainable in the weak sense (due to low technical upkeep costs). In the strong sense, only sustainable "e-" initiatives leave behind explicit public information and social resources to enable future decisionmakers to understand the context of previous decisions. (Democratic executives make most decisions outside the public deliberative theatre recorded in Hansards and annual reports.) Via "e-" open government initiatives, ICTs, and practices, old democratic staples of printed records filtered through a filtering media begrudgingly give way to many stakeholder eyes. "e-" enables participants to plan for timescales as long as democratic decision-making, but explicitly considers future access to decisions and to stakeholder discussions.

Weak sustainability: Despite examples of procedural and personal challenges identified in section 2, the "e-" infrastructures and procedures studied continue to facilitate project advancement without requiring expensive direct personal contact, elections, or divisive confrontations characterizing non-"e-" democratic interactions. "e-" tries to flexibly enable every stakeholder to choose their own degree of interaction with decision-making mechanisms, and to provide more substantial interactions than simply voting periodically or writing hateful letters.

Legacy sustainability: Easy access to information enables stakeholders to rapidly locate insightful and knowledgeable individuals with inputs to offer. "e-" did not change the importance of expert tacit knowledge, but potentially made existing kinds of explicit knowledge more accessible. "e-" as a method to extend existing democratic decision-making may or may not progress-being bound by meatspace requirements such as geographic constituencies, rules of information flow and practice, jurisdiction, etc.-but "e-" as its own decision-making practice remains to be optimized as technical, scientific, and other decision-making bodies adopt "e-".

\subsection{Participation}

"e-" is not for everyone. Challenges include stakeholders, policy makers, and implementers who lack ICT competency to access or evaluate data via "e-", or knowledge to engage a public policy space. However, the tradition of participating in non-"e-" democratic decision-making has been weakening for some time despite the lack of new types of access or knowledge challenges. ICT skills are fast becoming generic to modern workforces-taught alongside reading, writing and arithmetic-unlike more specific democracy skills.

Free discussion and consensus-making: Difficulty connecting human identities to online identities has hampered law enforcement and frustrated state governments concerned with geographic constituencies whose residents use global ICTs for local communications. Although ARIN examples showed that "e-" may address decisions related to geography, it is not so limited. Nature does not apportion challenges or opportunities according to man-made lines. Geographic individuals as the unit of representation, deliberation, and action should not be viewed as the default for "e-", or for the new kinds of challenges addressable by "e-". Party-based or representative politics have been a clumsy solution to map complex constellations of individual interests to party proxies who are the least disagreeable of the available candidates. By contrast "e-" enables all participants to access and use all information at all times to provide direct feedback 
about each issue. (Whether and how stakeholders access these capabilities, or develop new beneficial or harmful habits remains to be seen.) With "e-", dissent from popular opinion can occur within the context of the regular process without privatizing discussion and information into other venues. The public consensuses of "e-" provide additional interpersonal social accountability, deliberately occluded by private voting.

Decision-making barriers: The ambiguous scope of decision-making authority, particularly in federations such as Canada and industry groups is often debated. Some decisions make sense to be made locally, others regionally, nationally, supranationally, or internationally. "e-" presently thrives in the macro scale (matching the Internet's default scopes of audience and interaction). It also thrives locally and scales to stakeholder needs as many activist groups and Open Source projects have shown. While "e-" bureaucracies (usually) explicitly and transparently implement the will of stakeholders, democratic bureaucracies are oriented to facilitate the will of the policy-makers and elected leaders as proxies for the stakeholders. In contrast to strong democratic separation of powers, "e-" leaders transparently provided direct mentorship, formal judgment and intervention in multiple roles according to their knowledge and expertise.

Knowledge and technical barriers: "e-" decision-making rejects the meatspace fiction voters could prospectively decide in an informed manner several years worth of policy with one action at the ballot box or poorly advertised consultation. Instead, "e-" provides context and multiple opportunities for experts and laypersons alike to contribute continuously to decisions. It enables stakeholders to persuade with reason instead of popularity. And it enables representatives (technical and other contributors) to directly understand stakeholder needs via highly detailed case descriptions, technical demonstrations, and direct open inspection. Thus, discovery and amelioration of knowledge gaps between representatives and stakeholders may be rapid for those with ICT skills. Against voting and offline consultations, "e-" participation draws abysmally few participants. However, "e-" appears very efficient in addressing diverse stakeholder desires as illustrated above. At worst, "e-" replicates outcomes of democratic practices of anonymous voting and regulated lobbying. But "e-" is transparent so it's possible-and the default case-for stakeholders to seek and identify lobbyists, stakeholders, influencers, and decision-makers.

\section{5. "e-" need not modify democracy}

This paper's goal was to analyse whether "e-" supplements democracy as an innovation, or whether "e-" provides another decision-making toolkit that may be used in place of democracy to achieve similar substantial outcomes via processes absent from the democratic toolkit. Neither "e-", nor this paper, seek to profoundly or generally revise the core concept of democracy. Instead, this paper highlights enormous differences (in values, goals, internal variety, and complexity) between democratic patterns (as studied here through indicators of participation, sustainability, and impact) and the potentially novel pattern of social organization denoted by "e-".

Just as e-mail does not simply or only carry postal mail over wires, but provides a different set of capabilities, "e-" does not simply supplement democracy. "e-" and democracy are both decisionmaking technologies, with distinct and complementary capabilities and uses. Once this concept is admitted, it is also realized that "e-", as just one of many decision-making technologies. We should aspire to use "e-" to address broader challenges of decision-making not previously approached with the democracy toolkit, not just those defined in terms of democracy (as outlined in Milakovich, 2010). The three organizations studied demonstrate that great public good can arise by using "e-" to fulfill substantially the same needs as democratic decision-making, but without using the configurations or components from the democratic toolkit. "e-" did not make existing democratic decision-making more efficient, but yielded better outcomes while trampling democratic principles. The "e-" enhanced decision-making processes were not recognizably democratic. Therefore,"e-" is potentially a radical innovation displacing democracy for some uses.

To advance in clear thinking, the "e-" prefix should refer either to democratic decision-making supplemented by ICTs to emulate or replace individual traditional tools (voting, consultation, 
newsletters, etc.), or to the practice of integrated decision-making originating from ICTs elaborated presently. It should not refer simultaneously to both.

\subsection{Caricature of "e-"}

If "e-" does not extend democracy, yet may be used to implement important features of democracy (and possibly meritocracy, technocracy, etc.), what might it be? Evidence from the three organizations' common "e-" tools in manners departing from democracy-supports the following preliminary caricature of "e-". "e-" should embody "rule for the affected", contrasting democracy's "rule by the people". Previous ICTs such as phone calls, letters, campaign literature, lobbying, broadcast debates, etc. only replicated democratic forms; "e-" as a practice upsets those forms. "e-":

1. views challenges and decisions through small but related sets of defined interests of each stakeholder role in context, not through each human's comprehensive amalgams of diverse interests;

2. publicly and perpetually holds contributors to account for their contributions and actions, but continuously and constructively corrects, forgives, and supports multiple tries to implement an idea, instead of providing only singular drastic assessments through voting;

3. explicitly provides disproportionately more influence to affected, knowledgeable, and participating stakeholders regardless of numeric size or geographic distribution; and

4. enables all stakeholders to directly influence all stages of decision-making and implementation in a comfortable manner through ubiquitous availability of information.

Such practices are broadly absent from, or hostile to, present implementations of democracy. Yet stakeholders have voluntarily yielded to apparently non-democratic restraints to achieve personally desirable outcomes through governance practices that enable broad sustainability.

Studying "e-" democracy to enhance decision-making requires recalling why democracy was implemented and valued in the ways we recognize and measure. We also need a solid basis from which to extrapolate about how and why "e-" is supposed to be different as a mode of interaction. Otherwise, we could not detect that "e-" is different, nor could we adjust our expectations accordingly. As a starting point, this paper has argued that "e-" may need to be more carefully conceptualized as being distinct from ICTs implementing "e-" or democracy. But we must wait until "e-" is used in many more contexts, and for many more stakeholders to access and use large open data sets and decisions provided by "e-", to understand what it means to organize by "e-".

Perhaps further work will find that "e-" is just "new governance" (e.g., Rhodes, 1996) at a different internal scale. Both "e-" and new governance are broadly inclusive, accessible, cooperative, and emulate or facilitate features of "democracy" where required. In either case, when adopting or studying "e-", we must not simply copy or assume democratic forms into "e-" without understanding their original reasons or functions.

\section{Conclusions}

This paper has used data from three globally significant organizations dependent on "e-" decision-making to show that "e-" is not a relevant modifier to democratic decision-making. "e-" is not an incremental innovation of democracy, but is instead a radical innovation providing a decision-making tool alongside democracy. Across many scales-from international commerce down to individual preferences, involving small through worldwide stakeholder communities-the practice of "e-" appears to be of common form, as though "e-" is an emerging platform or paradigm (Kuhn, 1962). This paper has also shown that important indicators of good democratic decisionmaking —namely: active participation, sustainability, and impact-fail to show that "e-" in reality provides inclusive, resilient, and responsive decision-making outcomes. 


\section{References}

Apache Software Foundation (2009). Apache HTTP Server Project Guidelines and Voting Rules. The Apache HTTP Server Project. Retrieved 1 Aug, 2009, from http://httpd.apache.org/dev/guidelines.html

Apache Software Foundation (2010). Bylaws of The Apache Software Foundation. The Apache HTTP Server Project. Retrieved 1 Aug, 2009, from http://apache.org/foundation/bylaws.html

ARIN (n.d.). ARIN History. American Registry for Internet Numbers. Retrieved 18 Sep, 2009, from https://www.arin.net/about us/history.html

ARIN (2010). BYLAWS OF AMERICAN REGISTRY FOR INTERNET NUMBERS, LTD. American Registry for Internet Numbers. Retrieved 30 June, 2010, from https://www.arin.net/about_us/corp_docs/bylaws.html

Arrow, K. (1974). The Limits of Organization. New York: Norton.

Benson, J.K. (1975). The Interorganizational Network as a Political Economy. Administrative Science Quarterly, 20(2): 229249.

Blachfellner, S., \& Edelmann, N., \& Parycek, P., \& Seböck, W., (2009). Editorial. JeDEM. 1(1): i-ii.

Bunce, V. (2003). Rethinking Recent Democratization: Lessons from the Postcommunist Experience. World Politics. 55(2): $167-192$.

Carpini, M.X.D., \& Cook, F.L. \& Jacobs, L.R. (2004). Public Deliberation, Discursive Participation, and Citizen Engagement: A Review of the Empirical Literature. Annual Review of Political Science. 7: 315-344.

Chadwick, A. (2008). Web 2.0: New Challenges for the Study of E-Democracy in an Era of Informational Exuberance. Department of Politics and International Relations/New Political Communication Unit, Royal Holloway, University of London.

Christensen, Tom; Lægreid, Per (2002). New Public Management: Puzzles of Democracy and the Influence of Citizens. Journal of Political Philosophy. 10(3): 267-295.

Dahl, R.A. (1994). A Democratic Dilemma: System Effectiveness versus Citizen Participation. Political Science Quarterly. 109(1): 23-34.

Davies, A., \& Lithwick, D., (2010). Government 2.0 and Access to Information: 1. Recent Developments in Proactive Disclosure and Open Data in Canada. Library of Parliament: Legal and Legislative Affairs Division, Parliamentary Information and Research Service. April 15, 2010.

Donovan, Todd. (2007). Direct Democracy as Super-Precedent: Political Constraints of Citizen-Initiated Laws. Willamette Law Review. 43:191-234.

Encyclopædia Britannica (2010). Democracy. Encyclopædia Britannica Online. Retrieved 20 Aug, 2010, from http://www.britannica.com/EBchecked/topic/157129/democracy

Ferro, E. \& Molinari, F. 2010). Making Sense of Gov 2.0 Strategies: 'No Citizens, No Party'. JeDEM. 2(1): 56-68.

Garcia, A.C., \& Standlee, A.I., \& Bechkoff, J., \& Cui, Y. (2009). Ethnographic Approaches to the Internet and ComputerMediated Communication. Journal of Contemporary Ethnography. 38(1): 52-84.

Henderson, R.M \& Clark, K.B. (1990). Architectural Innovation: The Reconfiguration Of Existing Product Technologies and the Failure of Established Firms. Administrative Science Quarterly. 35(1): 9-30.

Johnsen, H.C.G., \& Normann, R., \& Fosse, J.K., (2005). Reflexive democracy: creating actionable knowledge through regional development coalitions. Al \& Society. 19(4): 442-46.

Jones, C. \& Hesterly, W.S., \& Borgatti, S.P. (1997). A General Theory of Network Governance: Exchange Conditions and Social Mechanisms. The Academy of Management Review. 22(4): 911-945.

Karrenberg, D., \& Ross, G. \& Wilson, P. \& Nobile, L. (2001). Development of the Regional Internet Registry System. The Internet Protocol Journal. 4 (4), 17-29.

Kaschesky, M., \& Riedl, R. (2010). Collaborative Tools for e-Participation across Networks. JeDEM. 2(1): 10-17.

Kirlin, J.J. (1996). The Big Questions of Public Administration in a Democracy. Public Administration Review. 56(5): 416423.

Kuhn, T. (1962). The Structure of Scientific Revolutions. Chicago: University of Chicago Press

Li, B. (2009). Innovation Governance at Three International Infrastructure Organizations. Presented at 4S 2009, Washington, DC.

Li, B. (2010). Open Source Innovation. Thesis, University of Calgary.

Morlino, L. (2002). What is a 'Good' Democracy? Theory and Empirical Analysis. Conference on "The European Union, Nations State, and the Quality of Democracy. Lessons from Southern Europe", University of California, Berkeley. 
Mozilla (n.d.). The Mozilla Manifesto. Mozilla Foundation. Retrieved 8 July, 2010, from http://www.mozilla.org/about/manifesto.en.html

Netcraft (2009). What's that site running? Netcraft, Ltd. Retrieved 10 Sep, 2009, from http://netcraft.com

Pildes, R.H. \& Anderson, E.S. (1990). Slinging Arrows at Democracy: Social Choice Theory, Value Pluralism, and Democratic Politics. Columbia Law Review. 90:2121-2214.

Plater, Z.J.B. (2006). Law, Media, \& Environmental Policy: A Fundamental Linkage in Sustainable Democratic Governance. Boston College Law School Faculty Papers. Boston College Law School Year 2006.

Schumpeter, J.A. (1942). Capitalism, socialism and democracy. New York: Harper.

Rhodes, RAW (1996). The New Governance: Governing without Government. Political Studies. 44:652-667.

Rowe, G., \& Frewer, L.J. (2000). Public Participation Methods: A Framework for Evaluation. Science, Technology, \& Human Values. 25(1): 3-29.

SourceForge (2010). About. Geeknet, Inc. Retrieved July 12, 2010, from http://sourceforge.net/about

USAID (1998). Handbook of Democracy and Governance Program Indicators. Technical Publication Series, August 1998. Center for Democracy and Governance, U.S. Agency for International Development, Washington, D.C. 20523-3100.

Utterback, J.M. (1995). Mastering the Dynamics of Innovation. Cambridge: Harvard University Press.

Waller, P. \& Livesey, P. \& Edin, K. (2001). e-Government in the Service of Democracy. ICA Information No. 74: General Issue. International Council for Information Technology in Government Administration.

World Commission on Environment and Development (1987). Report of the World Commission on Environment and Development: Our Common Future. Chapter 2. Oxford: Oxford University Press.

\section{About the Author}

Ben $\mathrm{Li}$

As a Research Associate at the University of Calgary examining innovation in city regions, as a Policy and Communication Analyst at the Legislative Assembly of Alberta engaging stakeholders, and as a freelance consultant with degrees in biology, political science and open source innovation, Ben has diverse interests. 